OPEN ACCESS

Edited by:

Wee-Jun Ong

Xiamen University Malaysia, Malaysia

Reviewed by:

Tianyi Ma,

University of Newcastle, Australia

Junkuo Gao,

Zhejiang Sci-Tech University, China

Lin Jing,

Beijing University of Technology, China

${ }^{*}$ Correspondence:

Kuang-Hsu Wu

kuang-hsu.wu@unsw.edu.au

Chunhui Tan

tanch_85@163.com

Zonghua Wang

wangzonghua@qdu.edu.cn

Specialty section

This article was submitted to Catalysis and Photocatalysis,

a section of the journal

Frontiers in Chemistry

Received: 06 August 2019

Accepted: 21 October 2019

Published: 08 November 2019

Citation:

Zhou Y, Zhang Y, Xu X, Zhao S,

Guo Z, Wu K-H, Tan C and Wang Z

(2019) Bimetallic Metal-Organic

Framework Derived Metal-Carbon

Hybrid for Efficient Reversible Oxygen

Electrocatalysis. Front. Chem. 7:747.

doi: 10.3389/fchem.2019.00747

\section{Bimetallic Metal-Organic Framework Derived Metal-Carbon Hybrid for Efficient Reversible Oxygen Electrocatalysis}

\author{
Yu Zhou ${ }^{1}$, Yan Zhang ${ }^{1}$, Xianzhen Xu ${ }^{1}$, Shenlong Zhao ${ }^{2}$, Ziyi Guo ${ }^{3}$, Kuang-Hsu Wu ${ }^{3 *}$, \\ Chunhui Tan $^{3 *}$ and Zonghua Wang ${ }^{1 *}$
}

${ }^{1}$ Shandong Sino-Japanese Center for Collaborative Research of Carbon Nanomaterials, College of Chemistry and Chemical Engineering, Qingdao University, Qingdao, China, ${ }^{2}$ School of Chemical and Biomolecular Engineering, The University of Sydney, Sydney, NSW, Australia, ${ }^{3}$ School of Chemical Engineering, The University of New South Wales, Kenginton, NSW, Australia

Development of cost-effective electrocatalysts for oxygen reduction reaction (ORR) and oxygen evolution reaction (OER) is key to enabling advanced electrochemical energy conversion technologies. Here, a novel nitrogen-doped metal-carbon hybrid (NiCo/CN) with a unique $3 \mathrm{D}$ hierarchical structure, consisting of uniformly distributed bimetallic nanoparticles encapsulated by partially graphitized $\mathrm{N}$-doped carbon shells, is fabricated by a one-step pyrolysis of a nanoscale metal-organic framework as precursor, which exhibits excellent activity for both ORR and OER. The surface chemical changes on the carbon hybrid probed by X-ray photoelectron spectroscopy (XPS) reveal the presence of favorable electronic interaction at the metal-nitrogen-carbon interface. Remarkably, the $\mathrm{NiCo} / \mathrm{CN}$ catalyst prepared at high temperature $\left(800^{\circ} \mathrm{C}\right)$ manifests a comparable performance to a commercial $\mathrm{Pt} / \mathrm{C}$ catalyst for the ORR, but also superior stability, path selectivity and methanol tolerance. On the other hand, the $E_{\text {onset }}(1.48 \mathrm{~V}$ vs.

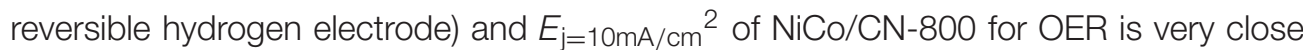

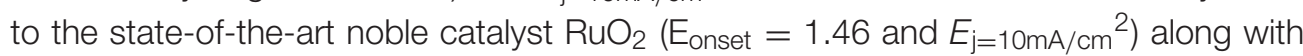
superior stability over $20 \mathrm{~h}$ of operation. The excellent catalytic property is attributable to the unique nanostructure, high porosity and the constructive synergistic effects of the elements $\mathrm{M}, \mathrm{N}$, and $\mathrm{C}$.

Keywords: metal-organic framework, NiCo alloy composites, bi-functional electrocatalyst, oxygen reduction reaction, oxygen evolution reaction

\section{INTRODUCTION}

Reversible oxygen reactions, including the oxygen reduction reaction (ORR) and oxygen evolution reaction (OER), are becoming increasingly important for many renewable conversion technologies and other important industrial processes (Pei et al., 2017; Gong et al., 2018; Zheng et al., 2019). Current benchmark catalysts for the ORR and OER are, respectively, Pt-based and Ir/Rubased materials. However, the high cost and scarcity of the noble metal substances greatly limit their wide applications (Hao et al., 2015). Furthermore, noble metal-based catalysts often suffer from multiple other drawbacks, including poor durability, impurity poisoning, and low 
selectivity, with detrimental effects to the environment on unregulated disposal (Zhao et al., 2019). Therefore, it is highly desirable to develop alternative ORR and OER catalysts with low cost (i.e., non-noble materials) and high performance for the sustainable energy technologies (Feng et al., 2016a,b).

Among various non-noble materials, heteroatom-doped nanocarbon hybrid materials with metal oxides and hydroxides manifested huge potential to be high-performance bifunctional electrocatalysts (Morozan et al., 2011). In particular, the doped nanocarbons with metal-nitrogen-carbon (M-N-C) centers attracted wide interest due to their excellent catalytic activity and durability. Recent reports indicated that nitrogen-doped M-N$\mathrm{C}$ hybrid catalysts can be compensable for the intrinsic deficiency in conductivity to a considerable extent, providing more efficient electron transfer between the catalytic sites and intermediates (Xia et al., 2015; Liu and Dai, 2016; You et al., 2016). Density functional theory (DFT) calculations further revealed that upon oxygen binding, there is a partial electronic interaction between the empty $d_{\mathrm{z}}$ orbitals of metal and the antibonding orbitals of oxygen, facilitating the subsequent catalytic steps (Artyushkova et al., 2017). Unfortunately, due to the low exposure of active sites and efficient mass transport, their overall performance is yet to meet the demand for a practical oxygen electrode.

Metal-organic frameworks (MOFs), as a new family of porous crystalline materials formed via self-assembly of metal ions and organic ligands (Furukawa et al., 2013; Zhu and Xu, 2014; Gao et al., 2018; Li C. et al., 2019; Li Y. et al., 2019), provide an ideal structural platform to create advanced metal-carbon hybrid electrocatalysts with unique properties, such as chemical composition versatility, high porosity and surface area (Ma et al., 2014a,b, 2016). However, due to the poor thermal stability of the single metal nodes, MOF-derived carbons usually suffer from a significantly reduced specific surface area that limits their catalytic application (Shui et al., 2015). Recently, it was shown that partial replacement of metal ions in the MOF framework by a second metal species with similar nature can not only retain their original structure but also endow more functionalities (Wang et al., 2016; Zhao et al., 2016; Fu et al., 2017). Therefore, designing bi-/multi-metallic MOF derivatives with favorable chemical compositions and desirable structure can be a promising strategy for developing cost-effective noble-metal-free electrocatalysts that can deliver a catalytic performance comparable to, or even better than, noble metal catalysts.

As reported, Cobalt (Co)-especially the Co- $\mathrm{Nx}$ speciescan greatly improve the oxygen reduction activity by reducing the adsorption of oxygen containing intermediates (Zhang et al., 2019). On the other hand, $\mathrm{Ni}$ is regarded as the most active transition metal for electrocatalytic oxygen evolution. Therefore, bimetallic carbon nanomaterial with $\mathrm{Co}$ and $\mathrm{Ni}$ could be an efficient electrocatalyst for both ORR and OER (Wang et al., 2018). Here, a porous heteroatom-doped carbon with the M-N-C structure derived from bimetallic MOFs was fabricated and used as bifunctional electrocatalysts for both ORR and OER. The structure and component of the asprepared $\mathrm{NiCo} / \mathrm{CN}-800$ are characterized by scanning electron microscopy (SEM), transmission electron microscopy (TEM), $\mathrm{X}$-ray diffraction (XRD), and nitrogen adsorption isotherm.
X-ray photoelectron spectroscopy (XPS) was also conducted to investigate the surface chemical states of the $\mathrm{NiCo} / \mathrm{CN}-800$ and the electronic interaction between $\mathrm{M}, \mathrm{N}$, and $\mathrm{C}$ atoms. Remarkably, the as-prepared NiCo/CN-800 exhibited similar catalytic activity but superior stability with prominent methanol tolerance to a commercial $20 \mathrm{wt} \% \mathrm{Pt} / \mathrm{C}$ catalyst for the ORR. Moreover, the hybrid catalyst could deliver an OER with an onset potential of $1.48 \mathrm{~V}$ (vs. reversible hydrogen electrode, RHE) and an over-potential of only $350 \mathrm{mV}$ to achieve a stable current density of $10 \mathrm{~mA} \mathrm{~cm} \mathrm{~cm}^{-2}$ for over $20 \mathrm{~h}$ testing. The outstanding ORR and OER catalytic properties are ascribed to the unique nanostructure, high porosity, and electronic synergistic effects of the elements $\mathrm{M}, \mathrm{N}$, and C. This concept provides a new strategy to design heteroatom-doped porous carbon-based nanomaterials for energy conversion applications including catalysis, supercapacitors, and rechargeable batteries.

\section{EXPERIMENTAL}

\section{Chemicals}

Nafion solution $(5 \%)$, platinum on graphitized carbon $(\mathrm{Pt} / \mathrm{C}$, $20 \mathrm{wt} \%$ ), was obtained from Sigma-Aldrich. 2-Methylimidazole $\left(\mathrm{C}_{4} \mathrm{H}_{6} \mathrm{~N}_{2}\right)$, Cobalt nitrate hexahydrate $\left(\mathrm{Co}\left(\mathrm{NO}_{3}\right)_{2} \cdot 6 \mathrm{H}_{2} \mathrm{O}\right)$, nickel nitrate $\left(\mathrm{Ni}\left(\mathrm{NO}_{3}\right)_{2} \cdot 6 \mathrm{H}_{2} \mathrm{O}\right)$, Polyvinyl -pyrrolidone (PVP) and Triethylamine $\left(\mathrm{C}_{6} \mathrm{H}_{15} \mathrm{~N}\right)$ were purchased from Aladdin. Methanol and hydrochloric acid were obtained from Shanghai Chemical Reagent Inc. All chemicals were used without further purification.

\section{Synthesis of NiCo/ZIF-67 Nanooctahedra}

Zeolitic imidazolate framework- 67 (ZIF-67) was prepared by the following procedure: $\mathrm{Co}\left(\mathrm{NO}_{3}\right)_{2} \cdot 6 \mathrm{H}_{2} \mathrm{O}(5.88 \mathrm{~g})$ and PVP $(5 \mathrm{~g})$ were dissolved in $500 \mathrm{~mL}$ methanol to form solution A. 2-Methylimidazole $(6.626 \mathrm{~g})$ and triethylamine $(0.4 \mathrm{~mL})$ were dissolved in another $500 \mathrm{~mL}$ methanol to form solution B. Solution B was then poured into solution A for $10 \mathrm{~min}$ under magnetic stirring. Subsequently, the mixed solution was aged at room temperature for $24 \mathrm{~h}$. The sample was collected by centrifugation and washed with methanol three times. Finally, the sample (ZIF-67) was dried under vacuum at $100^{\circ} \mathrm{C}$ for $24 \mathrm{~h}$ (Zhang et al., 2017).

A tunable in-situ doped bimetallic ZIF-67 (Ni-Co) was also prepared, and the specific steps are as follows: preparing solution A: $\mathrm{Co}\left(\mathrm{NO}_{3}\right)_{2} \cdot 6 \mathrm{H}_{2} \mathrm{O}, \mathrm{Ni}\left(\mathrm{NO}_{3}\right)_{2} \cdot 6 \mathrm{H}_{2} \mathrm{O}$ (total $5.88 \mathrm{~g}$ ). The doping ratio was $10,20,30,40,50,60,70,80$, and 100\%) and PVP (5 g) was dissolved in $500 \mathrm{~mL}$ methanol to form solution A. The rest of the processes were identical to the above process.

\section{Synthesis of the Series of NiCo/CN-n Composites}

The as-prepared NiCo/ZIF-67 was pyrolyzed to $\mathrm{NiCo} / \mathrm{CN}-\mathrm{n}$ composites. A total of $500 \mathrm{mg}$ NiCo/ZIF-67 powers was placed in a silica boat and carbonized at $600,700,800$, and $900^{\circ} \mathrm{C}$ in a tube furnace. The carbonized temperature was elevated with a heating speed of $5^{\circ} \mathrm{C} \mathrm{min}^{-1}$ and maintained for $3 \mathrm{~h}$ under Argon

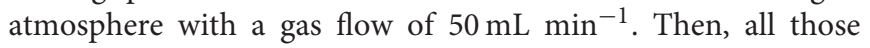
products were immersed in hydrochloric acid for $12 \mathrm{~h}$. After 
centrifugation, the $\mathrm{NiCo} / \mathrm{CN}-600, \mathrm{NiCo} / \mathrm{CN}-700, \mathrm{NiCo} / \mathrm{CN}-800$, and $\mathrm{NiCo} / \mathrm{CN}-900$ products were obtained at $600,700,800$, and $900^{\circ} \mathrm{C}$.

\section{Characterization}

The morphologies of the power were obtained by SEM images on Nova NanoSEM 450. Transmission electron microscope (TEM) images were taken by Tecnai G2 F20. The Powder XRD patterns were obtained by using a D-MAX 2500/PC with a graphitemonochromated $\mathrm{Cu} \mathrm{Ka}$ radiation source. XPS was obtained by using a ThermoFisher ESCALAB 250xi. Raman spectrum was measured on a LabRAM HR-800 Raman spectrometer. The nitrogen adsorption and desorption isotherms measurements were carried out by AutoChemi II 2920 at $77 \mathrm{~K}$.

\section{Electrochemical Measurements}

A conventional three-electrode was used for electrochemical measurements by using a VSP-300 electrochemical workstation (Bio-Logic SAS, France) at $25^{\circ} \mathrm{C}$. A total of $0.3 \mathrm{~mL}$ alcohol, $0.3 \mathrm{~mL}$ deionized water, $0.05 \mathrm{~mL}$ Nafion solution (5 wt\%), and $5 \mathrm{mg}$ $\mathrm{NiCo} / \mathrm{CN}-\mathrm{n}$ or Pt/C catalysts was adequately mixed together by ultrasonic agitation. Next, $8 \mathrm{uL}$ of the mixture was dropped onto the clear glassy carbon disk electrode (diameter $=0.4 \mathrm{~cm}$ ), which was used as a working electrode. A platinum wire and an $\mathrm{Ag} / \mathrm{AgCl}$ were utilized as a counter electrode and a reference electrode, respectively. During the measurement, $\mathrm{O}_{2}$-saturated alkaline $\mathrm{M}$ $\mathrm{KOH}$ aqueous solution was used as the electrolyte.

Cyclic voltammetry (CV) was scanned at a rate of $50 \mathrm{mV} \cdot \mathrm{s}^{-1}$ in the potential range from 0 to $-0.8 \mathrm{~V}$. The rotating disk electrode (RDE) measurement used varying speeds from 400 to $2,025 \mathrm{rpm}$ at a scanning rate of $5 \mathrm{mV} \cdot \mathrm{s}^{-1}$. The rotating ringdisk electrode (RRDE) measurement was used at a rotating speed of $1,600 \mathrm{rpm}$ at a scanning rate of $5 \mathrm{mV} \cdot \mathrm{s}^{-1}$ in $\mathrm{O}_{2}$-saturated $0.1 \mathrm{M} \mathrm{KOH}$ aqueous solution. The electron transfer number $(n)$ was calculated on the basis of the Koutecky-Levich equation (Naveen et al., 2017):

$$
\begin{aligned}
1 / J & =1 / J_{\mathrm{L}}+1 / J_{\mathrm{K}}=1 / B \omega^{0.5}+1 / J_{\mathrm{K}} \\
B & =0.62 n F C_{0} D_{0}^{2 / 3} v^{-1 / 6}
\end{aligned}
$$

where $J$ was the measured current density, $J_{\mathrm{K}}$ and $J_{\mathrm{L}}$ were the kinetic- and diffusion-limiting current densities, $\omega$ was the angular velocity, $F$ was the Faraday constant, $C_{0}$ was the bulk concentration of $\mathrm{O}_{2}$ and $v$ was the kinematic viscosity of the electrolyte.

Another efficient method to estimate the electron transfer number ( $n$ ) was based on the RRDE measurements, with the following equation (Naveen et al., 2017):

$$
n=4 I_{\mathrm{d}}\left(I_{\mathrm{d}}+I_{\mathrm{r}} / N\right)
$$

where $I_{\mathrm{d}}$ is disk current and $I_{\mathrm{r}}$ the ring current, and $N$ is the current collection efficiency ( 0.43$)$ for the Pt ring.

\section{RESULTS AND DISCUSSION}

\section{Synthesis, Structure, and Composition of Composites}

ZIF-67 was synthesized by the solvothermal reaction (Zhang et al., 2017), and the as-prepared sample was chosen as a precursor for ORR/OER electrocatalyst. Then, NiCo/ZIF-67 (replace metal nickel by in-situ replacement from ZIF-67) was transformed into the $\mathrm{NiCo} / \mathrm{CN}$ via carbonization and acidification. The precursors were pyrolyzed at $600,700,800$, and $900^{\circ} \mathrm{C}$, namely $\mathrm{NiCo} / \mathrm{CN}-600$, NiCo/CN-700, $\mathrm{NiCo} / \mathrm{CN}-800$, and $\mathrm{NiCo} / \mathrm{CN}-900$, respectively. At the same time, the proportion of bi-metal was adjusted to further explore the electrocatalytic properties. As shown in the SI (Supporting Information) the LSV of the different doping ratios and different pyrolysis temperatures is compared in Figure $\mathrm{S1}$ and $\mathrm{NiCo} / \mathrm{CN}$ (40\%) at different pyrolysis temperatures is shown in Figure S2. The results show that when the doping ratio is around $40 \%$ and the pyrolysis temperature is about $800^{\circ} \mathrm{C}$, the obtained catalyst exhibits the highest electrocatalytic activities among all the samples. So, the doping ratio (40\%) and the pyrolysis temperature $\left(800^{\circ} \mathrm{C}\right)$ were chosen to synthesize in this work.

Morphology of the as-prepared NiCo/ZIF-67 and its derivative $(\mathrm{NiCo} / \mathrm{CN}-800)$ were characterized by SEM and TEM techniques (Figure 1). Figures 1A,C show that NiCo/ZIF67 possesses a polygonal three-dimensional structure with an average size of $\sim 90 \mathrm{~nm}$. High-resolution TEM images in Figures $\mathbf{1 B}, \mathbf{D}$ indicate that the three-dimensional structure was well preserved after pyrolysis. Compared with Figure S3, the as-prepared NiCo/ZIF-67 well inherits the morphology and structural feature of ZIF-67 (Wang et al., 2013; Zhang et al., 2017). This translated structure laid a good foundation for electrocatalysis at the heterogeneous surface. To investigate the component of the as-prepared catalysts, TEM mapping and energy dispersive X-ray (EDX) microanalysis are carried
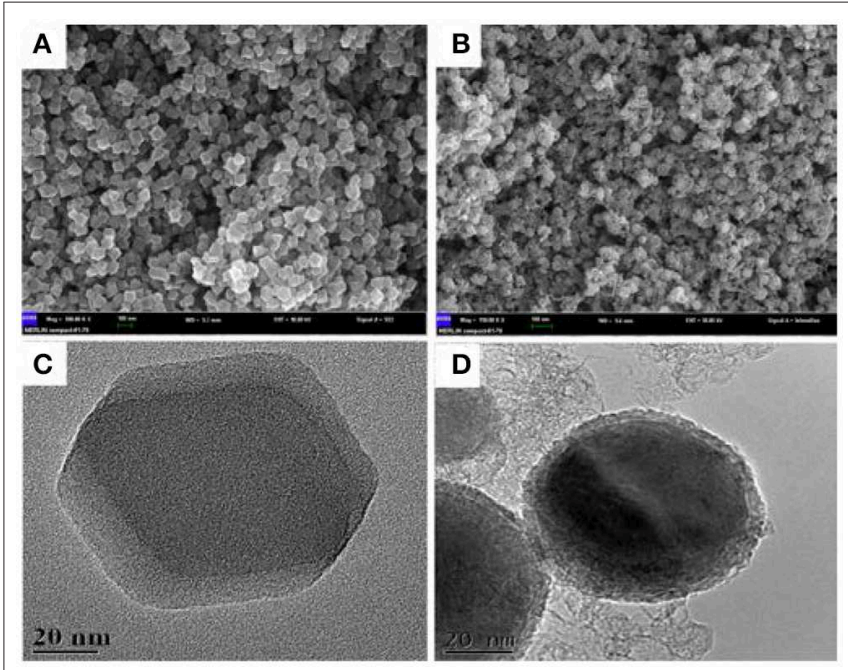

FIGURE 1 | SEM (A,B) and TEM (C,D) image of NiCo/ZIF-67 (A,C), and $\mathrm{NiCo} / \mathrm{CN}-800$ (B,D). 

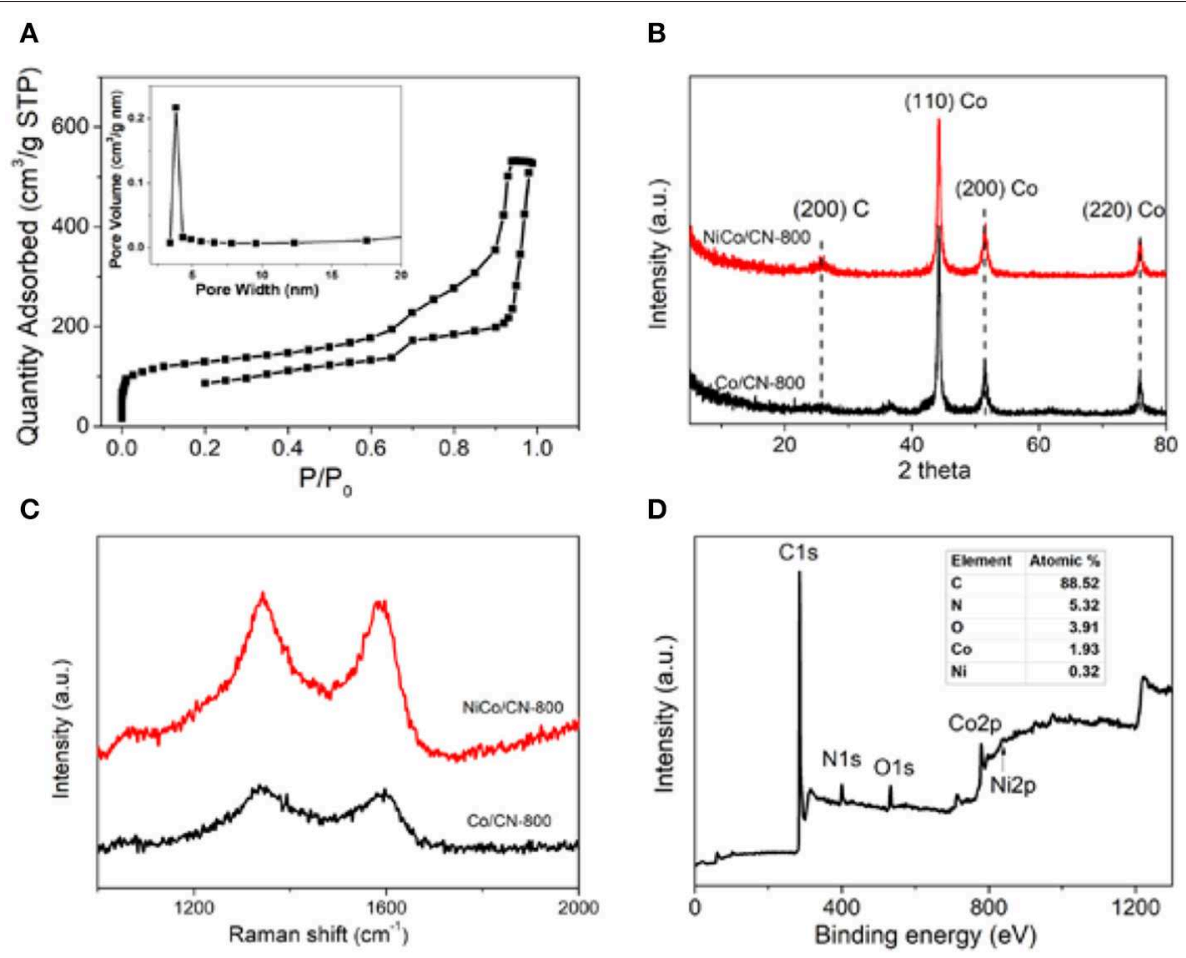

FIGURE 2 | (A) $\mathrm{N}_{2}$ adsorption-desorption isotherm of NiCo/CN-800; inset is the corresponding pore size distribution. (B) XRD patterns of the Co/CN-800 and $\mathrm{NiCo/CN-800.} \mathrm{(C)} \mathrm{Raman} \mathrm{patterns} \mathrm{of} \mathrm{the} \mathrm{Co/CN-800} \mathrm{and} \mathrm{NiCo/CN-800.} \mathrm{(D)} \mathrm{Survey} \mathrm{spectrum} \mathrm{of} \mathrm{NiCo/CN-800.}$

out. As show in Figure S4 the TEM-mapping images show C, $\mathrm{N}, \mathrm{O}, \mathrm{Co}$, and $\mathrm{Ni}$ elements are well dispersed on the surface of $\mathrm{NiCo} / \mathrm{CN}-800$. Besides, TEM-EDX microanalysis indicates the content is $88.16,5.66,3.78,2.04$, and $0.36 \%$ for $\mathrm{C}, \mathrm{N}, \mathrm{O}$, $\mathrm{Co}$, and $\mathrm{Ni}$, respectively, which is consistent with the result of XPS.

The specific surface area and pore structure of $\mathrm{NiCo} / \mathrm{CN}$ 800 were investigated by $\mathrm{N}_{2}$ adsorption isotherms. In Figure 2, the isotherm of the as-prepared $\mathrm{NiCo} / \mathrm{CN}-800$ sample shows a typical profile for a mesoporous material, and the specific surface area was found to be $558 \mathrm{~m}^{2} / \mathrm{g}$. The pore distribution indicates that the pore size is about $3.8 \mathrm{~nm}$ (inset of Figure 2). The isotherm of the as-prepared NiCo/ZIF-67 sample is shown in Figure S5. The specific surface area was found to be $408 \mathrm{~m}^{2} / \mathrm{g}$. Clearly, the MOF derivative has a large specific surface area and a desirable pore size distribution, retained after pyrolysis. These advantages are derived from the inherent characteristics of the $\mathrm{NiCo} / \mathrm{ZIF}-67$ precursor, which would benefit the mass transport during the electrocatalysis. In addition, the $\mathrm{N}_{2}$ adsorptiondesorption isotherm of the carbonized product of Ni-ZIF and ZIF-67 are shown in Figure S6. The presence of crystalline species was characterized by XRD. Figure $2 B$ shows that there are some distinct characteristic peaks of inorganic carbon and metal crystal lattice. $\mathrm{NiCo} / \mathrm{CN}-800$ has a large amount of disordered graphitic carbon (200) at $2 \theta=25^{\circ}$ after high temperature treatment, with some metallic species as indicated by the (110), (200), and (220) crystal planes (Hou et al., 2015, 2016). The degree of graphitization was measured by Raman spectroscopy as shown in Figure 2C. The peak at $1,590 \mathrm{~cm}^{-1}$ is ascribed to the $\mathrm{sp}^{2}$ vibration in the graphite layer, or the $\mathrm{G}$ band. The peak at $1,320-1,330 \mathrm{~cm}^{-1}$ is assigned to the $\mathrm{sp}^{3}$ vibration of the amorphous carbon structure, or the $\mathrm{D}$ band. The ratio of the relative intensities of the two peaks, $I_{\mathrm{D}} / I_{\mathrm{G}}$, reflects the level of graphitization of both degree of disorder and degree of defects. The $\mathrm{I}_{\mathrm{D}} / \mathrm{I}_{\mathrm{G}}$ ratio was calculated to be 0.89 and 0.98 for $\mathrm{Co} / \mathrm{CN}$ 800 and $\mathrm{NiCo} / \mathrm{CN}-800$, respectively. That is, after doping with $\mathrm{Ni}$, the disorder degree of carbon is improved, and the $\mathrm{NiCo} / \mathrm{CN}-$ 800 composites have more defect structures, which can provide electrocatalysis active sites, and is beneficial to the conduction of electrons (Liu et al., 2016).

To further explore the composition and structure of $\mathrm{NiCo} / \mathrm{CN}-800$, XPS was conducted to analyze the element types and scales. As shown in Figure 2D, NiCo/CN-800 is mainly composed of five elements: C, N, O, Co, and Ni accounting for $88.52,5.32,3.91,1.93$, and $0.32 \%$ (inset in Figure 2D), respectively. The carbon derived from the precursor itself is high in content, which can be improved by high-temperature carbonization. Additionally, the $\mathrm{N}$ content in the resultant $\mathrm{NiCo} / \mathrm{CN}-800$ is up to $5.32 \%$, which could enhance the extent of defects, increase the active site and promote the catalytic activity (Xia et al., 2015; Liu and Dai, 2016; You et al., 2016). The presence of $\mathrm{Ni}$ and Co provides strong evidence for successful bimetallic doping. In general, the $\mathrm{Co}$ and $\mathrm{Ni}$ sites are regarded as the active species for ORR and OER, respectively. In particular, 


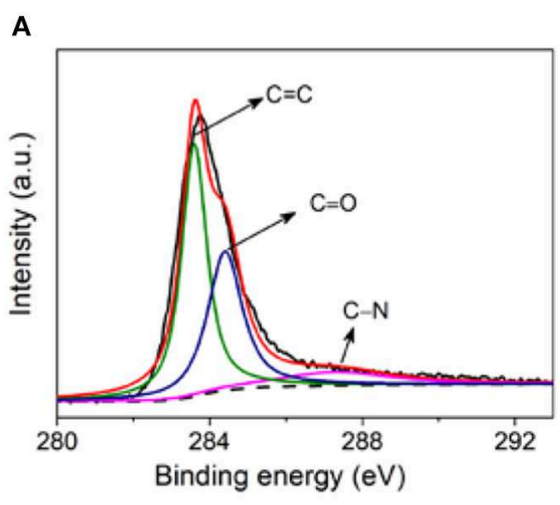

C

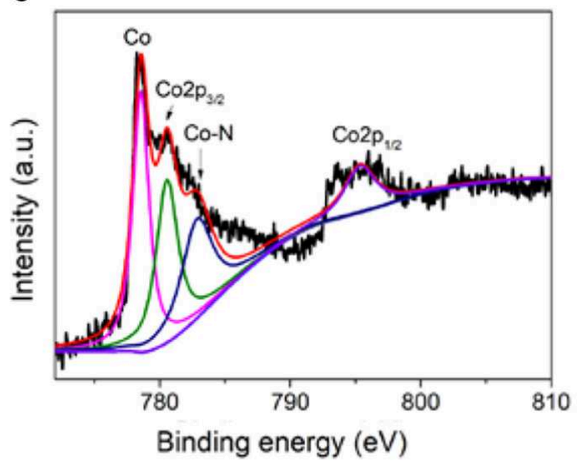

B

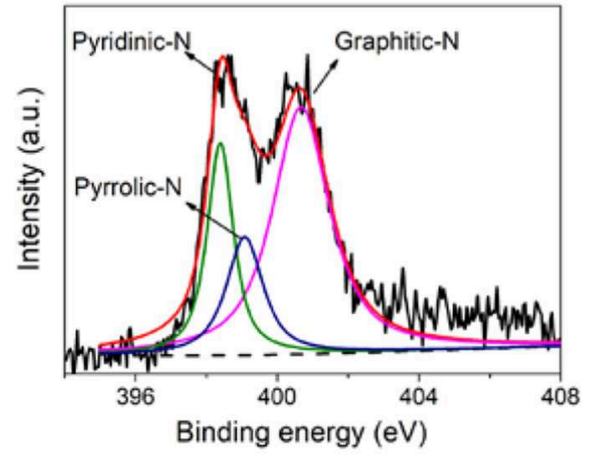

D

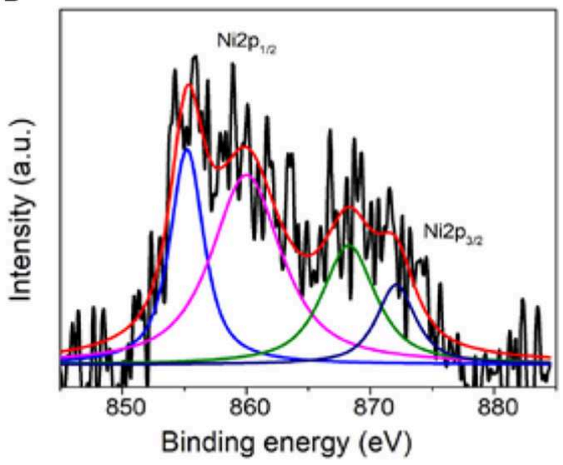

FIGURE 3 | (A) XPS C1s binding energy spectrum of NiCo/CN-800, (B) N1s binding energy spectrum, (C) Co2p binding energy spectrum, and (D) Ni binding energy spectrum.

the interaction between $\mathrm{Ni}$ and $\mathrm{Co}$ can further improve the oxygen-evolving reactions.

In addition, the specific chemical states of $\mathrm{C}$ and $\mathrm{N}$ in the sample were also analyzed. Since carbon is the main component of the prepared non-precious carbon-based materials, the highresolution XPS spectrum of C1s was firstly analyzed in Figure 3A. The C1s XPS spectrum exhibits several characteristic peaks at $284.8,286.9$, and $288.5 \mathrm{eV}$, corresponding to $\mathrm{C}=\mathrm{C}, \mathrm{C}-$ $\mathrm{N}$, and $\mathrm{C}=\mathrm{O}$, respectively. The $\mathrm{N} 1 \mathrm{~s}$ XPS spectrum in Figure 3B shows three characteristic peaks at 398.7, 400.15, and $401.3 \mathrm{eV}$, corresponding to $\mathrm{N}$ of pyridine, pyrrole, and graphite, respectively. Figure $3 \mathrm{C}$ is the binding energy spectrum of Co2p, Co, Co $2 \mathrm{p}_{1 / 2}, \operatorname{Co} 2 \mathrm{p}_{3 / 2}$, and Co-N. It is further confirmed that nitrogen also successfully binds to cobalt and increases more active sites (Dominguez et al., 2010; Hou et al., 2012; He et al., 2013; Su et al., 2014). On the other hand, in Figure 3D, the four peaks located at 855.2, 860.1, 868.2, and $872.2 \mathrm{eV}$ show the exitance of metallic $\mathrm{Ni}, \mathrm{Ni} 2 \mathrm{p}_{1 / 2}, \mathrm{Ni} 2 \mathrm{p}_{3 / 2}$, and $\mathrm{Ni}-\mathrm{N}$, demonstrating the coexistence of $\mathrm{Ni}$ and Co elements ( $\mathrm{Pu}$ et al., 2016; Li Y. et al., 2019).

\section{Electrochemical Characterization of $\mathrm{NiCo} / \mathrm{CN}-800$}

Subsequently, the electrochemical tests using the conventional three-electrode system were conducted to investigate the relationship between material structure and electrochemical performance. Figure 4 is the cyclic voltammetry curve $(\mathrm{CV})$ of
$\mathrm{NiCo} / \mathrm{CN}-800$ in a $0.1 \mathrm{M} \mathrm{KOH}$ solution at a sweep rate of 50 $\mathrm{mV} / \mathrm{s}$. Figure $4 \mathrm{~A}$ shows the $\mathrm{CV}$ curve of $\mathrm{NiCo} / \mathrm{CN}-800$ under $\mathrm{N}_{2}$-saturated or $\mathrm{O}_{2}$-saturated atmosphere. NiCo/CN-800 has no obvious peak under the $\mathrm{N}_{2}$-saturated solution, whereas an obvious reduction peak appears at $0.78 \mathrm{~V}$ (vs. RHE) under $\mathrm{O}_{2}$ saturated solution, indicating a good catalytic activity for ORR. Figure 4B shows the $\mathrm{CV}$ curves of $\mathrm{NiCo} / \mathrm{ZIF}-67$ and $\mathrm{NiCo} / \mathrm{CN}-$ 800 under $\mathrm{O}_{2}$-saturated solution. As shown in Figure 4B, a welldefined $\mathrm{O}_{2}$ reduction peak centered at ca. $0.76 \mathrm{~V}$ (vs. RHE) emerges when the electrolyte solution is saturated with $\mathrm{O}_{2}$. As a comparison, under the identical experimental condition, a weak $\mathrm{O}_{2}$ reduction peak is located at $0.45 \mathrm{~V}$ for initial NiCo/ZIF-67, verifying that the oxygen reduction potential is greatly improved after converting ZIF-67 into NiCo/CN-800.

To further explore the catalytic performance of $\mathrm{NiCo} / \mathrm{CN}-$ 800 , we performed the electrocatalytic performance and electron transfer number of $\mathrm{NiCo} / \mathrm{CN}-800$ by using a rotating disk electrode and a rotating ring disk electrode. Figure 5A shows the LSV curve of NiCo/ZIF-67, NiCo/CN-800, and commercial Pt/C (20 wt\%) tested in $0.1 \mathrm{M} \mathrm{KOH}$ aqueous solution with a rotation rate of 1,600 rpm. The diffusion-limited current densities of $\mathrm{NiCo} / \mathrm{ZIF}-67, \mathrm{NiCo} / \mathrm{CN}-800$, and commercial Pt/C (20 wt\%) were $0.9,6.7$, and $6.1 \mathrm{~mA} / \mathrm{cm}^{2}$, respectively. Compared with $\mathrm{NiCo} / \mathrm{ZIF}-67$, the ORR activity of $\mathrm{NiCo} / \mathrm{CN}-800$ significantly enhanced, indicating that the high-temperature carbonization is beneficial to enhancing the oxygen reduction performance. The initial potential of $\mathrm{NiCo} / \mathrm{CN}-800$ is $0.92 \mathrm{~V}$, which is better 

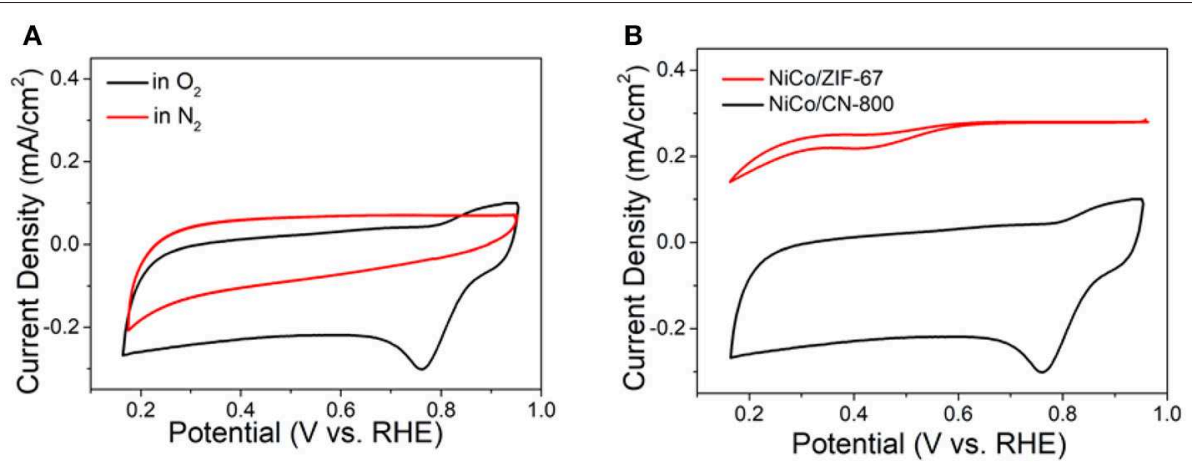

FIGURE 4 | CV curves in the $0.1 \mathrm{M} \mathrm{KOH}$. (A) CV curves of the carbonized material in $\mathrm{O}_{2}$ (black) and $\mathrm{N}_{2}$-saturated solutions (red), respectively. (B) CV curves of the $\mathrm{NiCo} / \mathrm{CN}-800$ and NiCo/ZIF-67.

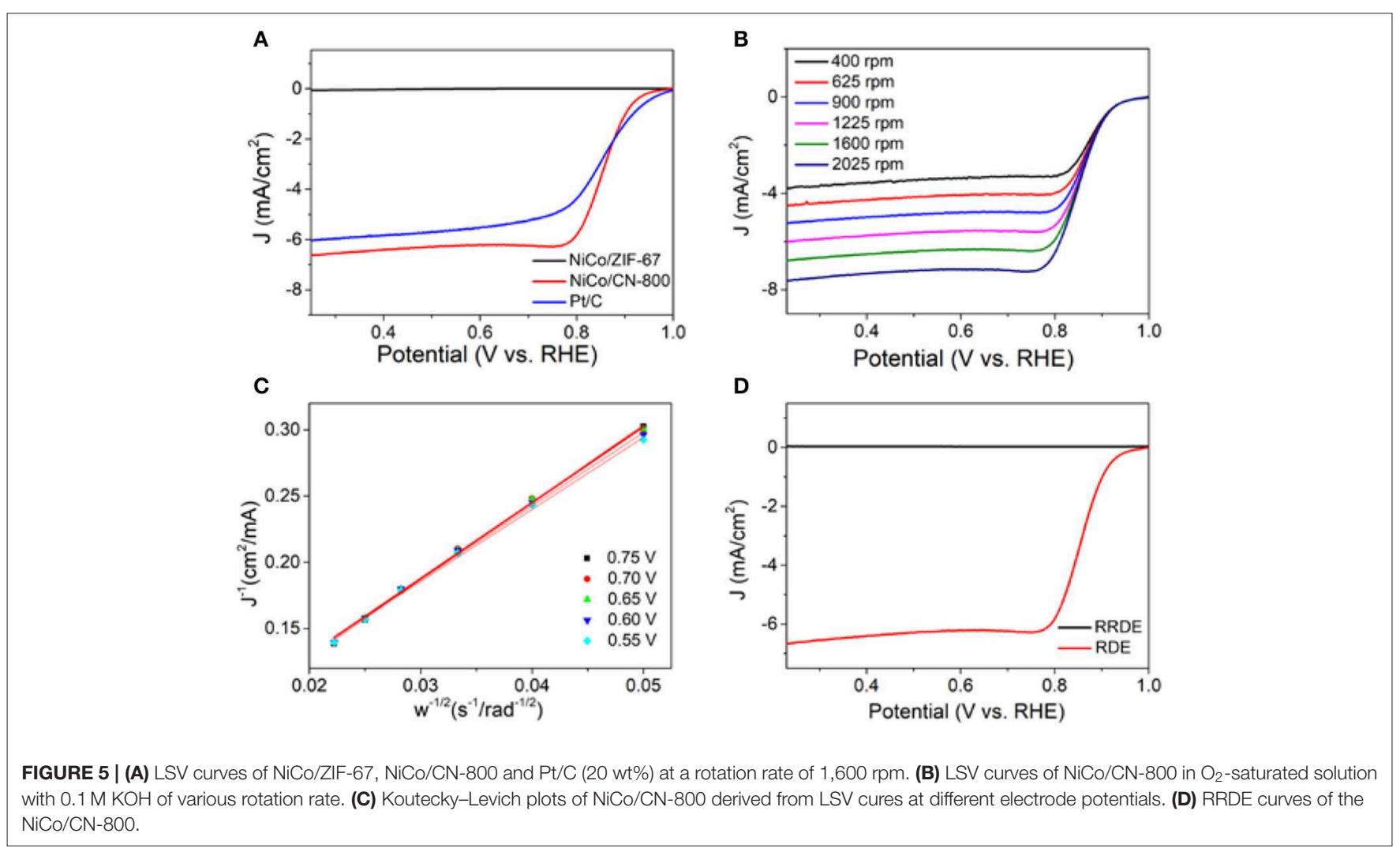

than the reported NiCo-based ORR catalysts (Table S1) and even comparable to commercial $\mathrm{Pt} / \mathrm{C}(0.96 \mathrm{~V})$, and the halfwave potential of $\mathrm{NiCo} / \mathrm{CN}-800(0.86 \mathrm{~V})$ is basically the same as that of commercial Pt/C $(0.85 \mathrm{~V})$. To further illustrate the ORR mechanism, the LSV curve with rotational speeds from 400 to $2,025 \mathrm{rpm}$ on the RDE is shown in Figure 5B. For ORR, electron transfer number $(n)$ is also an important parameter to measure the electrocatalytic performance. The corresponding KouteckyLevich $(\mathrm{K}-\mathrm{L})$ plots $\left(J^{-1}\right.$ vs. $\left.\omega^{1 / 2}\right)$ were obtained according to the standard method (Figure 5C). The linear plots showed the firstorder reaction kinetics toward oxygen (Mayrhofer et al., 2008). Based on the K-L equation, $n$ of $\mathrm{NiCo} / \mathrm{CN}-800$ was 3.92 in the potential range from 0.55 to $0.75 \mathrm{~V}$, which is very close to the ideal four-electron transfer process. Next, in order to further explain the electrocatalytic performance and better mass transfer studies, the kinetics of $\mathrm{NiCo} / \mathrm{CN}-800$ was also measured by a rotating ring-disk electrode (RRDE) under the same conditions in Figure 5D. The electron transfer number $(n)$ of $\mathrm{NiCo} / \mathrm{CN}-800$ was calculated to be 3.95. Those result showed that the state of oxygen reduction on the $\mathrm{NiCo} / \mathrm{CN}-800$ electrode is approaching $100 \%$ of the four-electron transfer, and it also indicates that the material has excellent catalytic efficiency.

In addition to catalytic activity, stability and methanol tolerance are also two key parameters for the practical application 

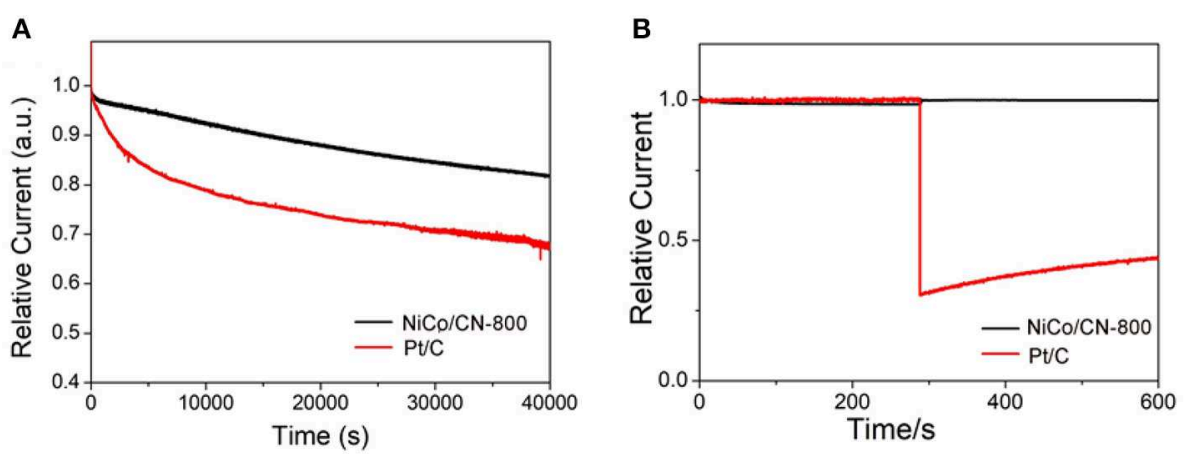

FIGURE 6 | (A) Current-time (i-t) chronoamperometric responses at -0.6 (vs. RHE) in $\mathrm{O}_{2}$-saturated $0.1 \mathrm{M} \mathrm{KOH}$ at NiCo/CN-800 and Pt/C electrodes (1,600 rpm) for 40,000 s. (B) Chronoamperometric responses at $-0.6 \mathrm{~V}$ in $\mathrm{O}_{2}$-saturated $0.1 \mathrm{M} \mathrm{KOH}$ at NiCo/CN-800 or Pt/C electrodes $(1,600 \mathrm{rpm})$ before and after addition of $1 \mathrm{M}$ methanol.
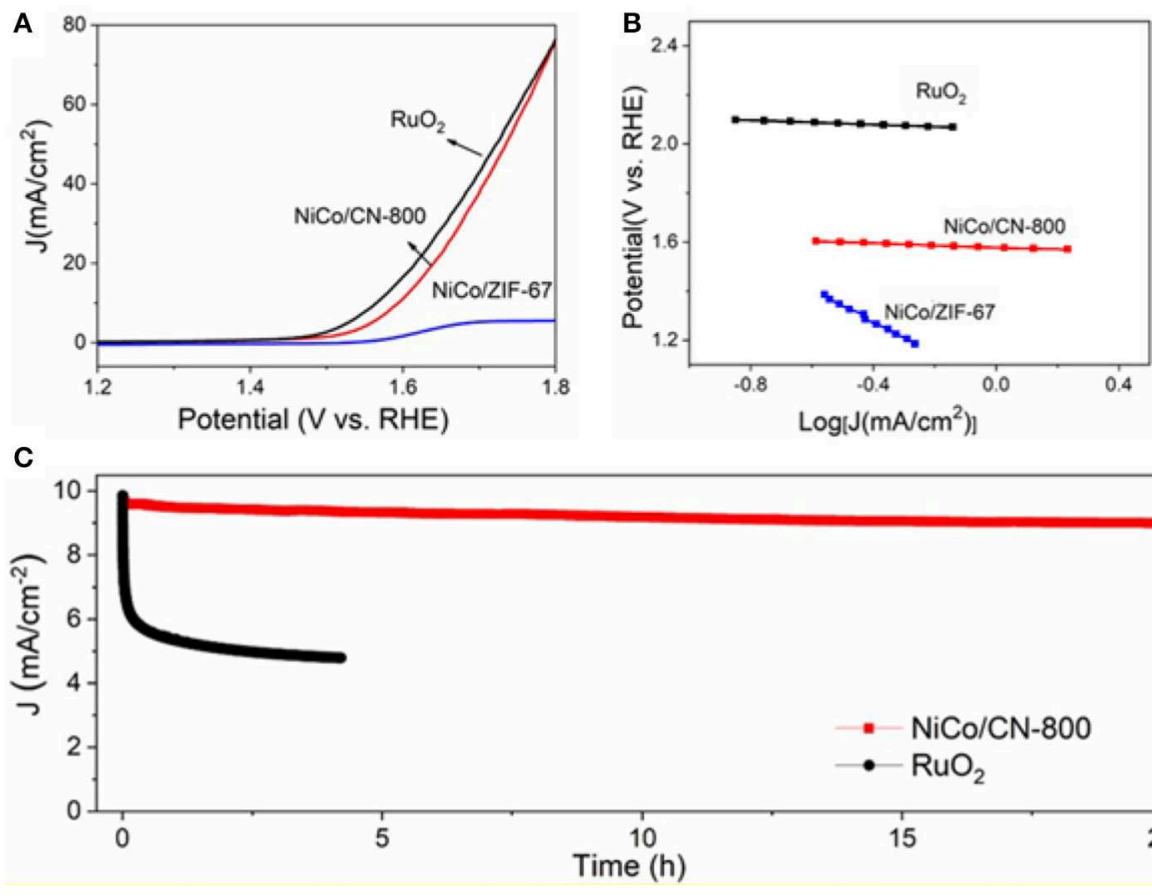

FIGURE 7 | (A) LSV polarization curves of NiCo/CN-800 and NiCo/ZIF-67; (B) the corresponding Tafel plots. (C) Durability of the as-prepared NiCo/CN-800 and commercial $\mathrm{RuO}_{2}$ under the high current density of $10 \mathrm{~mA} / \mathrm{cm}^{-2}$.

in fuel cells. The stability test of $\mathrm{NiCo} / \mathrm{CN}-800$ was shown in Figure 6A using a chronoamperometry at $-0.6 \mathrm{~V}$ (vs. RHE) and in $\mathrm{O}_{2}$ saturated $0.1 \mathrm{M} \mathrm{KOH}$ electrolyte at $1,600 \mathrm{rpm}$. As a comparison, $\mathrm{Pt} / \mathrm{C}(20 \mathrm{wt} \%)$ was also measured under the same experimental conditions. After $40,000 \mathrm{~s}$, a current density loss at the $\mathrm{NiCo} / \mathrm{CN}-800$ catalyst was about $17 \%$, and the corresponding loss at $\mathrm{Pt} / \mathrm{C}$ was as high as $31 \%$. This shows that the stability of the $\mathrm{NiCo} / \mathrm{CN}-800$ catalyst for ORR is better than that of the commercial $\mathrm{Pt} / \mathrm{C}$ catalyst. Chronoamperometric responses of $\mathrm{NiCo} / \mathrm{CN}-800$ and $\mathrm{Pt} / \mathrm{C}$ electrodes were investigated in Figure 6B. After injecting $1 \mathrm{M}$ methanol at 300th $\mathrm{s}$, the voltammetric current of the $\mathrm{NiCo} / \mathrm{CN}-800$ catalyst was nearly without change, whereas an observed current attenuation can be seen for commercial Pt/C, demonstrating the excellent selectivity of the as-prepared $\mathrm{NiCo} / \mathrm{CN}-800$ catalyst. These results indicate that the $\mathrm{NiCo} / \mathrm{CN}-800$ catalyst not only maintains high stability in an alkaline solution but also has high selectivity and outstanding methanol tolerance for ORR.

The electrode for OER performance evaluation was prepared by homogeneously depositing $0.25 \mathrm{mg} \mathrm{cm}^{-2}$ of as-synthesized $\mathrm{NiCo} / \mathrm{CN}-800$ onto a glassy carbon (GC) supporting electrode. The initial measurements were carried out in a standard threeelectrode cell containing $1.0 \mathrm{M} \mathrm{KOH}$ solution at a scan rate of $10 \mathrm{mV} \mathrm{s}^{-1}$ to minimize capacitive background current. 
In Figure 7A, a sharply increased anodic current response started at an onset potential $\left(E_{\text {onset }}\right)$ of $1.48 \mathrm{~V}$ (defined as a potential required for reaching an OER current density of $0.2 \mathrm{~mA} \mathrm{~cm}^{-2}$ ) is observed from the $\mathrm{NiCo} / \mathrm{CN}-800$ electrode, indicating a markedly improved catalytic activity compared to that of the NiCo/ZIF-67. Besides the $E_{\text {onset }}$, the operational potential at $10 \mathrm{~mA} \mathrm{~cm}{ }^{-2}\left(E_{\mathrm{j}=10}\right)$ is another key parameter for OER performance evaluation. When the thermodynamic OER potential $\left(\mathrm{E}^{0}{ }_{\mathrm{H} 2 \mathrm{O} / \mathrm{O} 2}=1.229 \mathrm{~V}\right)$ is used as the reference, the $\mathrm{NiCo} / \mathrm{CN}-800$ electrode possesses a low overpotential of $\sim 350 \mathrm{mV}$ at $10 \mathrm{~mA} \mathrm{~cm}^{-2}$, which is very close to that of the noble metal $\left(\mathrm{RuO}_{2}\right)$ catalysts $(\sim 330 \mathrm{mV})$. Interestingly enough, the overpotential of $\mathrm{NiCo} / \mathrm{CN}-800$ at a high current density of $80 \mathrm{~mA} \mathrm{~cm}^{-2}$ is the same as that of the commercial $\mathrm{RuO}_{2}$, which is ascribed to the excellent gas diffusion and mass transfer of the porous $\mathrm{NiCo} / \mathrm{CN}-800$. Subsequently, the catalytic kinetics of $\mathrm{NiCo} / \mathrm{CN}-800$ is assessed by the Tafel plots in an $\mathrm{O}_{2}$-saturated $1 \mathrm{M} \mathrm{KOH}$ solution. As displayed in Figure 7B, the resultant Tafel slope of $\mathrm{NiCo} / \mathrm{CN}-800\left(65 \mathrm{mV} \mathrm{dec}{ }^{-1}\right)$ is much smaller than that of NiCo/ZIF-67 $\left(155 \mathrm{mV} \mathrm{dec}^{-1}\right)$ and comparable to the commercial $\mathrm{RuO}_{2}\left(60 \mathrm{mV} \mathrm{dec}{ }^{-1}\right)$, signifying a superior reaction kinetics (Lee et al., 2012; Aijaz et al., 2016). Other than the catalytic activity, the robustness and durability are also key parameters to evaluate the performance of the catalyst. As shown in Figure 7C, under a constant current density of $10 \mathrm{~mA} / \mathrm{cm}^{-2}$, only $8.6 \%$ decay in anodic current is observed after $20 \mathrm{~h}$ of continuous electrolysis, which is obviously superior to that of the commercial $\mathrm{RuO}_{2}$ catalyst. The excellent stability should be mainly attributed to the porous structure of the as-prepared $\mathrm{NiCo} / \mathrm{CN}-800$.

\section{CONCLUSIONS}

In summary, a series of $\mathrm{N}$-doped bimetallic metal-carbon hybrid catalysts ( $\mathrm{NiCo} / \mathrm{CNs}$ ) derived from NiCo/ZIF-67 were successfully prepared by one-step pyrolysis for use as an efficient bifunctional electrocatalyst for both ORR and OER. The structural merits of the $\mathrm{NiCo} / \mathrm{CN}-800$ catalysts were revealed by $\mathrm{N}_{2}$ adsorption isotherm, XRD, XPS, and Raman

\section{REFERENCES}

Aijaz, A., Masa, J., Rösler, C., Xia, W., Weide, P., Botz, A. J., et al. (2016). Co@Co3O4 encapsulated in carbon nanotube-grafted nitrogen-doped carbon polyhedra as an advanced bifunctional oxygen electrode. Angew. Chem. Int. Ed. 55, 4087-4091. doi: 10.1002/anie.201509382

Artyushkova, K., Matanovic, O., Halevi, B., and Atanassov, P. (2017). Oxygen binding to active sites of $\mathrm{Fe}-\mathrm{N}-\mathrm{C}$ ORR electrocatalysts observed by ambientpressure XPS. J. Phys. Chem. 121, 2836-2843. doi: 10.1021/acs.jpcc.6b 11721

Dominguez, M., Taboada, E., Idriss, H., Molins, E., and Llorca, J. (2010). Fast and efficient hydrogen generation catalyzed by cobalt talc nanolayers dispersed in silica aerogel. J. Mater. Chem. 20, 4875-4883. doi: 10.1039/c0jm0 $0184 \mathrm{~h}$

Feng, J. X., Xu, H., Dong, Y. T., Ye, S. H., Tong, Y. X., and Li, G. R. (2016a). $\mathrm{FeOOH} / \mathrm{Co} / \mathrm{FeOOH}$ hybrid nanotube arrays as high-performance electrocatalysts for the oxygen evolution reaction. Angew. Chem. 55, 3694-3698. doi: 10.1002/anie.201511447 spectroscopy. The resultant $\mathrm{N}$-doped mesoporous $\mathrm{NiCo} / \mathrm{CN}-800$ exhibits superior catalytic activity and excellent durability as a bifunctional ORR and OER catalyst, which is close to and, in some cases, even better than that of noble metal catalysts $(\mathrm{Pt} / \mathrm{C}$ and $\mathrm{RuO}_{2} / \mathrm{C}$ ). The active dopants, porous structure and the good electron transfer ability are believed to significantly expedite the ORR and OER processes. This proof-of-concept study lays a solid foundation for the further exploration and development of nanostructured MOF derivatives for electrocatalysis and energy conversion applications such as metal-air batteries and supercapacitors.

\section{DATA AVAILABILITY STATEMENT}

All datasets generated for this study are included in the article/Supplementary Material.

\section{AUTHOR CONTRIBUTIONS}

$\mathrm{ZW}, \mathrm{CT}$, and K-HW proposed the research direction and guided the project. YZho and YZha designed and performed the experiments. YZho, YZha, and XX analyzed and discussed the experimental results and drafted the manuscript. YZho, YZha, ZG, and SZ joined the discussion of data and gave useful suggestions.

\section{FUNDING}

This work was supported by the Natural Science Foundation of China (Grant No. 21703115), the Provincial Key Research and Development Program of Shandong (Public Welfare Subject, 2018 GGX102030), and the Taishan Scholar Program of Shandong Province (ts201511027).

\section{SUPPLEMENTARY MATERIAL}

The Supplementary Material for this article can be found online at: https://www.frontiersin.org/articles/10.3389/fchem. 2019.00747/full\#supplementary-material

Feng, J. X., Ye, S. H., Xu, H., Tong, Y. X., and Li, G. R. (2016b). Design and synthesis of $\mathrm{FeOOH} / \mathrm{CeO}_{2}$ heterolayered nanotube electrocatalysts for the oxygen evolution reaction. Adv. Mater. 28, 4698-4703. doi: 10.1002/adma.201600054

Fu, Y., Yu, H. Y., Jiang, C., Zhang, T. H., Zhan, R., Li, X. W., et al. (2017). NiCo alloy nanoparticles decorated on $\mathrm{N}$-doped carbon nanofibers as highly active and durable oxygen electrocatalyst. Adv. Funct. Mater. 28:1705094. doi: 10.1002/adfm.201705094

Furukawa, H., Cordova, K. E., O’Keeffe, M., and Yaghi, O. M. (2013). The chemistry and applications of metal-organic frameworks. Science. 341:1230444. doi: 10.1126/science.1230444

Gao, J., Cong, J., Wu, Y., Sun, L., Yao, J., and Chen, B. (2018). Bimetallic Hofmanntype metal-organic framework nanoparticles for efficient electrocatalysis of oxygen evolution reaction. ACS Appl. Energy Mater. 1, 5140-5144. doi: 10.1021/acsaem.8b01229

Gong, K., Du, F., Xia, Z., Durstock, M., and Dai, L. (2018). Nitrogendoped carbon nanotube arrays with high electrocatalytic activity for oxygen reduction. Science. 323, 760-764. doi: 10.1126/science. 1168049 
Hao, C. X., Wen, F. S., Xiang, J. Y., Yuan, S. J., Yang, B. C., and Li, L. (2015). Liquid-exfoliated black phosphorous nanosheet thin films for flexible resistive random access memory applications. Adv. Funct. Mater. 26, 3314-3323. doi: 10.1002/adfm.201504187

He, Q. G., Li, Q., Khene, S., Ren, X. M., Lopez-Suarez, F. E., Lozano-Castello, D., et al. (2013). High-loading cobalt oxide coupled with nitrogen-doped graphene for oxygen reduction in anion-exchange-membrane alkaline fuel cells. J. Phys. Chem. C 117, 8697-8707. doi: 10.1021/jp401814f

Hou, Y., Yuan, H., Wen, Z. H., Cui, S. M., Guo, X. R., He, Z., et al. (2015). Advanced nitrogen-doped graphene/cobalt-embedded porous carbon polyhedron hybrid for efficient catalysis of oxygen reduction and water splitting. Adv. Funct. Mater. 25, 872-882. doi: 10.1002/adfm.201403657

Hou, Y., Yuan, H., Wen, Z. H., Cui, S. M., Guo, X. R., He, Z., et al. (2016). Nitrogendoped graphene/CoNi alloy encased within bamboo-like carbon nanotube hybrids as cathode catalysts in microbial fuel cells. J. Power Sources. 307, 561-568. doi: 10.1016/j.jpowsour.2016.01.018

Hou, Y., Zuo, F., Ma, Q., Wang, C., Bartels, L., and Feng, P. Y. (2012). $\mathrm{Ag}_{3} \mathrm{PO}_{4}$ oxygen evolution photocatalyst employing synergistic action of $\mathrm{Ag} / \mathrm{AgBr}$ nanoparticles and graphene sheets. J. Phys. Chem. C 116, 20132-20139. doi: $10.1021 /$ jp303219j

Lee, Y., Suntivich, J., May, K. J., Perry, E. E., and Shao-Horn, Y. (2012). Synthesis and activities of rutile $\mathrm{IrO}_{2}$ and $\mathrm{RuO}_{2}$ nanoparticles for oxygen evolution in acid and alkaline solutions. J. Phys. Chem. Lett. 3, 399-404. doi: $10.1021 / \mathrm{jz} 2016507$

Li, C., Xu, H., Gao, J., Du, W., Shangguan, L., Zhang, X., et al. (2019). Tunable titanium metal-organic frameworks with infinite $1 \mathrm{D}$ Ti-O rods for efficient visible-light-driven photocatalytic $\mathrm{H}_{2}$ evolution. J. Mater. Chem. A 7, 11928-11933. doi: 10.1039/C9TA01942A

Li, Y., Lu, M., Wu, Y., Xu, H., Gao, J., and Yao, J. (2019). Trimetallic metal-organic framework derived carbon-based nanoflower electrocatalysts for efficient overall water splitting. Adv. Mater. Interfaces 6:1900290. doi: 10.1002/admi.201900290

Liu, S. W., Zhang, H. M., Zhao, Q., Zhang, X., Liu, R. G., Fe, X., et al. (2016). Metal-organic framework derived nitrogen-doped porous carbon@graphene sandwich-like structured composites as bifunctional electrocatalysts for oxygen reduction and evolution reactions. Carbon. 106, 74-83. doi: 10.1016/j.carbon.2016.05.021

Liu, X., and Dai, L. (2016). Carbon-based metal-free catalysts. Nat. Rev. Mater. 1:16064. doi: $10.1038 /$ natrevmats.2016.64

Ma, T. Y., Dai, S., Jaroniec, M., and Qiao, S. Z. (2014a). Graphitic carbon nitride nanosheet-carbon nanotube three-dimensional porous composites as highperformance oxygen evolution electrocatalysts. Angew. Chem. Int. Ed. 53, 7281-7285. doi: 10.1002/anie.201403946

Ma, T. Y., Dai, S., Jaroniec, M., and Qiao, S. Z. (2014b). Metal-organic framework derived hybrid $\mathrm{Co}_{3} \mathrm{O}_{4}$-carbon porous nanowire arrays as reversible oxygen evolution electrodes. J. Am. Chem. Soc. 136, 13925-13931. doi: $10.1021 /$ ja5082553

Ma, T. Y., Dai, S., and Qiao, S. Z. (2016). Self-supported electrocatalysts for advanced energy conversion processes. Mater. Today 19, 265-273. doi: 10.1016/j.mattod.2015.10.012

Mayrhofer, K. J. J., Strmcnik, D., Blizanac, B. B., Stamenkovic, V., Arenz, M., and Markovic, N. M. (2008). Measurement of oxygen reduction activities via the rotating disc electrode method: from pt model surfaces to carbonsupported high surface area catalysts. Electrochim. Acta 53, 3181-3188. doi: 10.1016/j.electacta.2007.11.057

Morozan, A., Jousselme, B., and Palacin, S. (2011). Low-platinum and platinumfree catalysts for the oxygen reduction reaction at fuel cell cathodes. Energy Environ. Sci. 4, 1238-1254. doi: 10.1039/c0ee00601g

Naveen, M. H., Shim, K., Hossain, M. S. A., Kim, J. H., and Shim, Y. B. (2017). Template free preparation of heteroatoms doped carbon spheres with trace fe for efficient oxygen reduction reaction and supercapacitor. Adv. Energy Mater. 7:1602002. doi: 10.1002/aenm.201602002

Pei, Z. X., Li, H. F., Huang, Y., Zhu, M. S., Wang, Z. F., and Zhi, C. Y. (2017). Texturing in situ: N,S-enriched hierarchically porous carbon as a highly active reversible oxygen electrocatalyst. Energy Environ. Sci. 10, 742-749. doi: 10.1039/C6EE03265F

Pu, J., Liu, Z., Ma, Z., Wang, J., Zhang, L., Chang, S., et al. (2016). Structure design of $\mathrm{NiCo}_{2} \mathrm{O}_{4}$ electrodes for high performance pseudocapacitors and lithium-ion batteries, J. Mater. Chem. A 4, 17394-17402. doi: 10.1039/C6TA 08198C

Shui, J., Chen, C., Grabstanowicz, L., Zhao, D., and Liu, D. J. (2015). Highly efficient nonprecious metal catalyst prepared with metal-organic framework in a continuous carbon nanofibrous network. Proc. Natl. Acad. Sci. U.S.A. 112, 10629-10634. doi: 10.1073/pnas.1507159112

Su, Y., Zhu, Y., Jiang, H., Shen, J., Yang, X., Zou, W., et al. (2014). Cobalt nanoparticles embedded in $\mathrm{N}$-doped carbon as an efficient bifunctional electrocatalyst for oxygen reduction and evolution reactions. Nanoscale. 6, 15080-15089. doi: 10.1039/C4NR04357J

Wang, L., Ambrosi, A., and Pumera, M. (2013). "Metal-free" catalytic oxygen reduction reaction on heteroatom-doped graphene is caused by trace metal impurities. Angew. Chem. 125, 14063-14066. doi: 10.1002/ange.201309171

Wang, X.-R., Liu, J.-Y., Liu, Z.-W., Wang, W.-C., Luo, J., Han, X.-P., et al. (2018). Identifying the key role of pyridinic-N-Co bonding in synergistic electrocatalysis for reversible ORR/OER. Adv. Mater. 30:1800005. doi: 10.1002/adma.201800005

Wang, Z. J., Lu, Y. Z., Yan, Y., Larissa, T. Y. P., Zhang, X., Wuu, D., et al. (2016). Core-shell carbon materials derived from metal-organic frameworks as an efficient oxygen bifunctional electrocatalyst. Nano Energy. 30, 368-378. doi: 10.1016/j.nanoen.2016.10.017

Xia, W., Mahmood, A., Liang, Z., Zou, R., and Guo, S. (2015). Earth-abundant nanomaterials for oxygen reduction. Angew. Chem. Int. Ed. 55, 2650-2676. doi: 10.1002/anie.201504830

You, B., Jiang, N., Sheng, M., Gul, S., Yano, J., and Sun, Y. (2016). High-performance overall water splitting electrocatalysts derived from cobalt-based metal-organic frameworks. Chem. Mater. 27, 7636-7642. doi: 10.1021/acs.chemmater.5b02877

Zhang, B.-W., Wang, Y.-X., Chou, S.-L., Liu, H.-K., and Dou, S.-X. (2019). Fabrication of superior single-atom catalysts toward diverse electrochemical reactions. Small Methods. 3:1800497. doi: 10.1002/smtd.201800497

Zhang, W., Jiang, X., Wang, X., Kaneti, Y. V., Chen, Y., Liu, J., et al. (2017). Spontaneous weaving of graphitic carbon networks synthesized by pyrolysis of ZIF-67 crystals. Angew. Chem. Int. Ed. 56, 8435-8440. doi: 10.1002/anie.201701252

Zhao, P. P., Hua, X., Luo, W., Chen, S. L., and Cheng, G. Z. (2016). Metal-organic framework-derived hybrid of $\mathrm{Fe}_{3} \mathrm{C}$ nanorod-encapsulated, $\mathrm{N}$-doped CNTs on porous carbon sheets for highly efficient oxygen reduction and water oxidation. Catal. Sci. Technol. 6, 6365-6371. doi: 10.1039/C6CY01031H

Zhao, S., Wang, D.-W., Amal, R., and Dai, L. (2019). Carbon-based metal-free catalysts for key reactions involved in energy conversion and storage. $A d v$. Mater. 31:1801526. doi: 10.1002/adma.201801526

Zheng, X. J., Wu, J., Cao, X. C., Abbott, J., Jin, C., Wang, H. B., et al. (2019). N$\mathrm{P}-$, and S-doped graphene-like carbon catalysts derived from onium salts with enhanced oxygen chemisorption for Zn-air battery cathodes. Appl. Catal. B 241, 442-451. doi: 10.1016/j.apcatb.2018.09.054

Zhu, Q. L., and Xu, Q. (2014). Metal-organic framework composites. Chem. Soc. Rev. 43, 5468-5512. doi: 10.1039/C3CS60472A

Conflict of Interest: The authors declare that the research was conducted in the absence of any commercial or financial relationships that could be construed as a potential conflict of interest.

Copyright (c) 2019 Zhou, Zhang, Xu, Zhao, Guo, Wu, Tan and Wang. This is an open-access article distributed under the terms of the Creative Commons Attribution License (CC BY). The use, distribution or reproduction in other forums is permitted, provided the original author(s) and the copyright owner(s) are credited and that the original publication in this journal is cited, in accordance with accepted academic practice. No use, distribution or reproduction is permitted which does not comply with these terms. 